\title{
Health issues and healthcare utilization among adults who reported exposure to tear gas during 2020 Portland (OR) protests: a cross-sectional survey
}

Britta N. Torgrimson-Ojerio ${ }^{1 *}$, Karen S. Mularski ${ }^{2}$, Madeline R. Peyton ${ }^{1}$, Erin M. Keast ${ }^{1}$, Asha Hassan ${ }^{3}$ and Ilya Ivlev ${ }^{1}$

\begin{abstract}
Background: Repeated use of chemical irritants for crowd-control by local and federal law enforcement during sustained racial justice protests in the U.S. has raised concerns about potential adverse health effects. The objective of this study was to describe the health consequences of exposure to tear gas agents and associated healthcare utilization among adults reporting recent exposure to tear gas.

Methods: A cross-sectional, self-administered web-based survey of a convenience sample of 2257 adults reporting recent exposure to tear gas in Portland, Oregon (U.S.), administered between July 30, 2020-August 20, 2020. Descriptive analyses were conducted on socioeconomic characteristics, reported health issues, utilization of healthcare services, and frequency of reported exposure to tear gas. Associations between reported mental health issues, healthcare utilization and race and/or ethnic categories were assessed using a chi-square test. For tests of association, racial and/or ethnic categories were divided into White/Non-Hispanic only and all other racial/ethnic categories due to a small number of Black, American Indian or Alaska Native, Asian/Pacific Islander, Hispanic participants and participants with multiple race and/or ethnic background. Effect sizes for the differences were expressed as Cramer's V, a metric that measures associations between nominal responses. The Cochran-Armitage trend test was used to assess the relationship between health issues and the number of reported days of exposure to tear gas (i.e., a proxy dose of exposure) grouped into 1 day, $2-4$ days, and $\geq 5$ days. Missing data (item nonresponse) were omitted from the analysis.
\end{abstract}

Results: Almost all respondents $(2116 ; 93.8 \%)$ reported physical $(2114 ; 93.7 \%)$ or psychological $(1635 ; 72.4 \%)$ health issues experienced immediately after (2105; 93.3\%) or days following (1944; 86.1\%) the exposure. A slightly higher proportion experienced delayed head or gastrointestinal tract issues compared with immediate complaints. The majority $(1233 ; 54.6 \%)$ reported receiving or planning to seek medical or mental care. We observed a positive exposure-response trend for all except mouth-related delayed issues $(p<0.01)$.

(Continued on next page)

\footnotetext{
* Correspondence: Britta.N.Torgrimson-Ojerio@kpchr.org

'Kaiser Permanente Northwest, Center for Health Research, 3800 N Interstate Ave, Portland, OR 97227, USA

Full list of author information is available at the end of the article
}

(c) The Author(s). 2021 Open Access This article is licensed under a Creative Commons Attribution 4.0 International License, which permits use, sharing, adaptation, distribution and reproduction in any medium or format, as long as you give appropriate credit to the original author(s) and the source, provide a link to the Creative Commons licence, and indicate if changes were made. The images or other third party material in this article are included in the article's Creative Commons licence, unless indicated otherwise in a credit line to the material. If material is not included in the article's Creative Commons licence and your intended use is not permitted by statutory regulation or exceeds the permitted use, you will need to obtain permission directly from the copyright holder. To view a copy of this licence, visit http://creativecommons.org/licenses/by/4.0/. The Creative Commons Public Domain Dedication waiver (http://creativecommons.org/publicdomain/zero/1.0/) applies to the data made available in this article, unless otherwise stated in a credit line to the data. 
(Continued from previous page)

Conclusion: Persons who reported exposer to tear gas agents also reported physical and psychological health issues over a multiple-day period. Health issues reported increased with the frequency of reported exposure, indicating a potential dose-response; these health effects often led to healthcare utilization. This study provides evidence of potential unexpected harms of tear gas in civilians.

Keywords: Healthcare utilization, Health effects, Crowd-control, Tear gas

\section{Background}

Although chemical irritants for crowd-control are increasingly used on civilians worldwide, there is no clear understanding of their potential harms on the general population [1]. Following the death of George Floyd, Jr. in May 2020 in Minneapolis, Minnesota, and the deaths of other Black Americans, instances of undue use [2] of police force, and the Black Lives Matter movement ignited ongoing protests against police brutality and systemic racism in Portland, Oregon, across the U.S. [3], and worldwide [4]. Between 15 and 26 million Americans participated [3] in nationwide protests during the first weeks of the 2020 protests. Oregon has a long history of racism, starting with sundowner laws, similar to other cities across the U.S., discriminatory policies and practices for Black persons [5]. Local and national activism surrounding inequities and calls to action have been ongoing; however, protests and crowd sizes surged upwards of thousands per night in Portland during the 100 consequtive nights of protests in 2020. As protesting crowd sizes rose, so did the use of riot control agents by law enforcement. There were single nights in Portland, OR when chemical munitions were used more than 20 times [6].

Although banned in warfare, civilians are subjected to chemical munitions when used by law enforcement agencies. Riot control agents (e.g., ortho-chlorobenzylidene-malononitrile-CS gas, 1chloroacetophenone- $\mathrm{CN}$ gas, and pepper spray-oleoresin capsicum $[\mathrm{OC}]$ ), denoted by the colloquial "tear gas," are used to disperse crowds. These chemical agents are considered non-lethal irritants [7] and were designed to cause short-term physical discomfort to people through irritation of the eyes, nose, and respiratory system [8] and not result in severe or irreversible health effects. Most safety data on these agents come from midtwentieth-century studies on animals and healthy young men [9]. However, health effects vary based on the type of chemicals used, proximity to deployment, and dose [10-12]. Handbooks on military medicine [13] and medical management of chemical casualties [14] suggest no serious harm to persons exposed to these chemical agents. However, data from real-world civilian exposures have documented (i) severe dermal, cardiopulmonary, ocular, and neurological injuries, (ii) permanent disabilities (e.g., blindness, loss of limbs), and even (iii) death due to respiratory arrest $[8,15,16]$. Detailed reports on healthcare utilization after tear gas exposures from emergency departments demonstrate various injuries that can result in hospitalization [12, 17]. Furthermore, concerns have been raised about the effects of police use of tear gas on mental health outcomes (e.g., depression, post-traumatic stress disorder) [18-21] and whether there is associated healthcare utilization.

Existing harms evidence in civilians appears to be insufficient to inform policy regarding the use of crowdcontrol agents in community settings. The short- and long-term effects of tear gas agents when used on women, children, pregnant persons, the elderly, and persons with pre-existing comorbidities, and associated utilization of healthcare remain understudied [1]. Because of reports of menstrual cycle disturbances from U.S. protesters exposed to tear gas, we sought to gather data on this phenomenon as endocrine effects of tear gas remain unstudied to date. The objective of this cross-sectional survey was to describe the health consequences of environmental exposure to tear gas agents and associated healthcare utilization among adults from the general population.

\section{Methods \\ Study design}

This was an anonymous, cross-sectional, selfadministered web-based survey. The survey was open from July 30 through August 20, 2020, in English and Spanish. All responses were optional. We used the STrengthening the Reporting of OBservational studies in Epidemiology (STROBE) checklist to guide the reporting of this study.

\section{Participants, setting, recruitment}

This survey was conducted to better understand health issues and healthcare utilization patterns in a convenience sample of adults who reported being exposed to tear gas agents in the city of Portland, Oregon. Participants were adults aged 18 or older answering two questions about the fact of and intensity of exposure to tear gas. Responses from males/cisgender men and transgender women were excluded from menstrual health 
outcomes questions. Participants needed access to the Internet to take the online survey.

We identified a social media site used by protesters and sought permission to post our survey, which led to social media uptake via Facebook, Twitter, Reddit, and Instagram re-postings. The web-link was later provided in a published interview by the first author in a major daily newspaper and its website (The Oregonian) and the Oregon Health Authority. No incentives were offered for participation.

\section{Variables and data sources/measurement}

To develop the survey items, we adapted the Centers for Disease Control and Prevention (CDC)'s list of known immediate and long-term health effects of exposure to riot control agents [22]. Based on anecdotal community reports, we added questions about menstrual, neurological, and mental health symptoms. Our survey included 38 questions regarding: (1) the fact of exposure to tear gas (place of exposure and the number of days exposed [i.e., proxy dose of exposure]), (2) physical and psychological health issues experienced immediately after and 1-2 days following the exposure, (3) menstrual changes, (4) utilization of healthcare services, (5) recent COVID-19 diagnosis, and (6) demographic characteristics (i.e., age, gender identity, and race and/or ethnicity). Participants were also offered an opportunity to share additional details via free text. Study data were collected and managed using Research Electronic Data Capture (REDCap) [23] tools hosted at Kaiser Permanente Center for Health Research.

\section{Statistical methods}

Descriptive analyses were conducted on socioeconomic characteristics, reported health issues, utilization of healthcare services, and frequency of exposure to tear gas or other chemical agents. Cisgender men and transgender women were excluded from analyses of menstrual symptoms. Associations between reported mental health issues, healthcare utilization and race and/or ethnicity were assessed using chi-square tests. For tests of association, racial/ethnic categories were divided into White/Non-Hispanic only and all other racial/ethnic categories due to a smaller proportion of Black, American Indian or Alaska Native Asian/Pacific Islander, and Hispanic, respondents and persons with multiple race and/ or ethnic background. Participants who did not provide race and/or ethnic information were excluded from tests of association by race. We used the chi-square test to evaluate a change in the frequency of mental health issues. Effect sizes for the differences were expressed as Cramer's $V$, a metric that measures associations between nominal responses [24, 25]. Cramer's $V$ value of $<0.1$ was considered negligible, 0.1 weak, 0.3 moderate, and
0.5 strong association. The Cochran-Armitage trend test was used to assess the relationship between health issues and number of days of exposure to tear gas (i.e., a proxy dose of exposure) grouped into 1 day, 2-4 days, and $\geq 5$ days. Missing data (item non-response) were omitted from the analysis. All calculations were carried out using IBM SPSS Statistics (V.24.0) and SAS/STAT ${ }^{\circledR}$ software (V.9.4).

\section{Qualitative data analysis}

This analysis aimed to explore qualitative responses and identify additional health concerns, context, and details not captured by the survey questions. Data were analyzed for all respondents who indicated that they had been exposed to any non-munition riot control agent, indicated the intensity of exposure, and provided answers to an open-ended question: "Is there anything else you would like to share with us? Did you experience any other symptoms you would like to describe?" To identify themes for this analysis, we used an inductive approach. The coding was conducted by an investigator experienced with qualitative methods.

\section{Results \\ Participants}

A total of 2450 persons accessed the survey (Fig. 1). Of those, 2257 (92.1\%) met qualifying criteria and were eligible for our analysis. Of the 2257 persons, 1998 (88.5\%) fully completed the survey. The majority self-identified as females/cisgender women (1151; $51.0 \%$ of 2257), White/non-Hispanic (1615; 71.6\%), and aged 18-33 years $(1199 ; 53.1 \%)$ (Table 1$)$. The respondents were younger than the general population in Portland, OR. The racial and ethnic composition of the respondents was considerably close to the city population, with the exception of the proportion of persons self-identified as American Indian or Alaska Native (i.e., 4.1\% among respondents vs. $0.8 \%$ in Portland, OR) and Black (2.6\% among respondents vs. 5.8\% in Portland, OR) [26]. The vast majority reported being exposed to tear gas at a protest (2099; 93.0\%); of those, most reported two to 4 days of exposure $(1391 ; 62.7 \%)$. A small number were exposed to tear gas only at their homes or elsewhere 158 (7.0\%). Twenty-eight respondents $(1.2 \%)$ reported a recent positive COVID-19 test.

\section{Post-exposure health effects}

Overall, 2116 (93.8\%) respondents reported physical (2114; 93.7\%) and/or psychological $(1635 ; 72.4 \%)$ health issues following tear gas exposure. Besides menstrual health issues, physical health issues were reported by 2105 (93.3\%) persons immediately after the exposure, abating to 1750 (77.5\%) after 1-2 days (i.e., delayed health issues). Respondents more frequently reported 


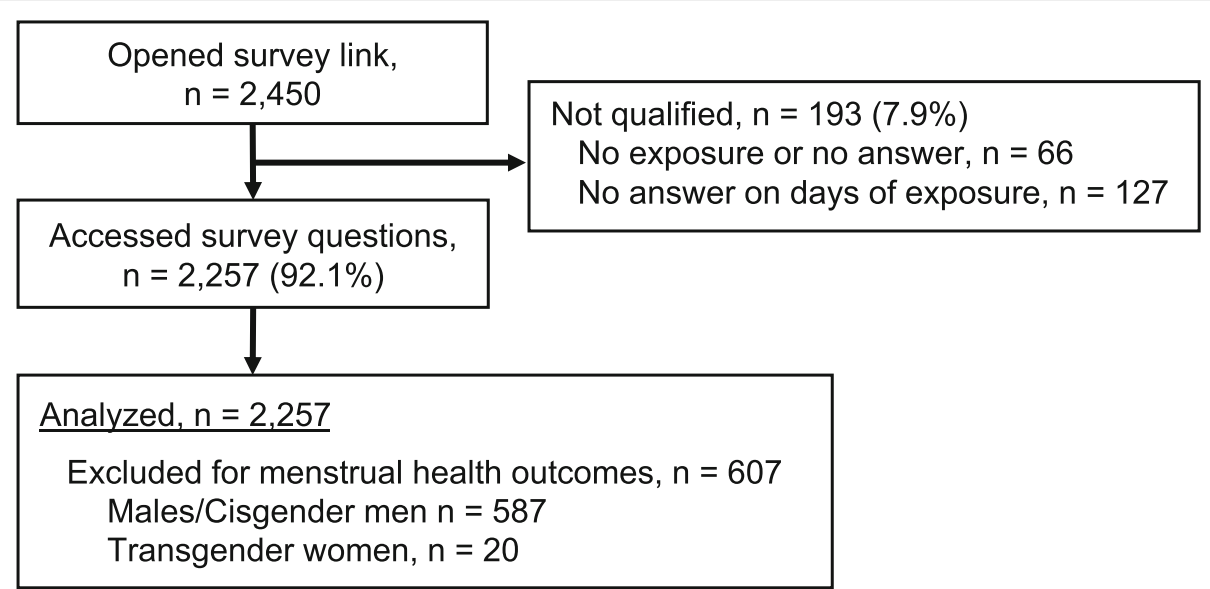

Fig. 1 Flow-diagram

eye, nose, mouth, skin, and/or lungs/chest issues immediately after the exposure vs. 1-2 days following (Table 2). A slightly higher proportion experienced delayed health issues related to head or gastrointestinal tract, compared with immediate complaints.

\section{Immediate physical health issues}

Almost all respondents $(2105 ; 93.3 \%)$ reported having eye, nose, lungs/chest, mouth, and/or skin-related issues immediately after the exposure (Table 2 and Additional file 1).

Of 1995 persons ( $88.4 \%$ of 2257$)$ reporting any eye issues, the largest group experienced eye burning (1895; 95.0\%), followed by excessive tearing (1713; 85.9\%), blurred vision (1392; 69.8\%), and eye redness (1078; $54.0 \%)$. Many participants reported issues related to the upper and lower respiratory tract and mouth. Of 1790 (79.3\% of 2257) individuals reporting any nose-related issues, most reported having a burning sensation (1529; $85.4 \%$ ) or runny nose $(1520 ; 84.9 \%)$. Of 1569 persons $(69.5 \%)$ with lung/chest issues, the largest group reported coughing (1442; 91.9\%), followed by shortness of breath $(1041 ; 66.3 \%)$, chest tightness $(1038 ; 66.2 \%)$, and choking sensation (872; 55.6\%). Mouth issues were reported by $1510(66.9 \%)$ of respondents, most commonly irritation $(1157 ; 76.6 \%)$, burning $(1074 ; 71.1 \%)$, or sore throat (1064; 70.5\%). Skin issues were reported by 1238 respondents $(54.9 \%)$, primarily burning sensation (1189; $96.0 \%)$, rash $(280 ; 22.6 \%)$, and burns $(180 ; 14.5 \%)$.

Fewer individuals reported any gastrointestinal- and head-related issues immediately after the exposure (453; $20.1 \%)$. The most common gastrointestinal issues were nausea $(371 ; 81.9 \%$ of 453$)$ and gastrointestinal cramping (263; 58.1\%). Of 610 persons reporting any head-related issues, respondents commonly cited headache (482; $79.0 \%$ ), disorientation (407; 66.7\%), and dizziness (356; $58.4 \%)$.

\section{Delayed physical health issues}

Most participants (1823; 80.8\%) reported delayed physical health issues after exposure (Table 2). The most commonly reported delayed issues were related to lungs and/or chest $(1063 ; 47.1 \%)$ and menstrual changes $(899$; $54.5 \%$ of 1650 respondents who potentially menstruate), followed by gastrointestinal $(638 ; 28.3 \%)$, head (626; $27.7 \%)$, and eye issues $(594 ; 26.3 \%)$.

Delayed health issues differed in frequency when compared to those endorsed immediately after the exposure. Respondents less frequently reported eye, nose, mouth, skin, and/or lungs/chest issues days following exposure vs. immediately after the exposure (Additional file 1). For example, 1713 persons reported experiencing excessive tearing immediately; that number was 163 one to 2 days later (90.5\% decline). Similar declines were seen for mouth burning (91.0\% decline), drooling (96.7\% decline), blurred vision ( $88.8 \%$ decline), eye burning ( $82.8 \%$ decline) nose burning (87.3\% decline), and choking sensation ( $86.4 \%$ decline). All changes were significantly significant $(p<0.01)$.

Although the frequency of most symptoms decreased within a few days, we observed a statistically significant increase in the frequency of composit gastrointestinal issues by $40.8 \%$ (453 [20.1\%] reported immediate gastrointestinal issues vs. 638 [28.3\%]) reported delayed issues; $p<0.01)$. The frequency of composit head-related issues have increased by $2.6 \%$ (from 610 [27.0\%] endorsed to 626 [27.7\%]); however, this increase was not statistically significut $2.6 \%(p=0.59)$. The most common increased gastrointestinal issues were new cases of diarrhea, gastroinstentinal cramping, and issues in the "Other" category (all $p<0.01$ ). An additional 200 persons reported diarrhea-a $137.9 \%$ increase compared with the day of exposure $(p<0.01)$. Gastrointestinal cramping was reported by an additional 161 persons-a $61.2 \%$ increase $(p<0.01)$. An additional $18.5 \%$ of respondents reported 
Table 1 Participants' characteristics

\begin{tabular}{|c|c|c|}
\hline Category & $\mathbf{n}$ & $\%(N=2257)$ \\
\hline \multicolumn{3}{|l|}{ Age, years } \\
\hline $18-33$ & 1199 & 53.1 \\
\hline $34-50$ & 706 & 31.3 \\
\hline$\geq 51$ & 122 & 5.4 \\
\hline Prefer Not to Answer & 230 & 10.2 \\
\hline \multicolumn{3}{|l|}{ Gender Identity } \\
\hline Female/Cisgender Woman & 1151 & 51.0 \\
\hline Male/Cisgender Man & 587 & 26.0 \\
\hline Genderqueer, not exclusively female or male & 162 & 7.2 \\
\hline Transgender woman & 20 & 0.9 \\
\hline Transgender man & 33 & 1.5 \\
\hline My gender identity is not listed here & 27 & 1.2 \\
\hline Prefer Not to Answer & 277 & 12.3 \\
\hline \multicolumn{3}{|l|}{ Race/Ethnicity } \\
\hline White, non-Hispanic & 1615 & 71.6 \\
\hline All other race/ethnicity & 377 & 16.7 \\
\hline Prefer not to answer & 265 & 11.7 \\
\hline \multicolumn{3}{|l|}{ Race/Ethnicity (not mutually exclusive) ${ }^{a}$} \\
\hline White & 1831 & 81.1 \\
\hline Black & 58 & 2.6 \\
\hline American Indian or Alaska Native & 93 & 4.1 \\
\hline Asian/Pacific Islander & 115 & 5.1 \\
\hline Hispanic & 174 & 7.7 \\
\hline Prefer not to answer & 265 & 11.7 \\
\hline \multicolumn{3}{|l|}{ Place of exposure to tear gas } \\
\hline At a protest & 2099 & 93.0 \\
\hline Other (i.e., homes, community) & 158 & 7.0 \\
\hline \multicolumn{3}{|l|}{ Intensity of exposure in days overall } \\
\hline 1 & 398 & 17.6 \\
\hline 2 to 4 & 1391 & 61.6 \\
\hline$\geq 5$ & 468 & 20.7 \\
\hline
\end{tabular}

${ }^{a}$ Respondents may be counted in multiple race/ethnicity categories

having headaches one or 2 days following the exposure $(p<0.01)$.

Of 1650 persons identified as female/cisgender woman, transgender man, genderqueer (not exclusively female or male), and those who did not specify their sex or gender identity, more than half-899 (54.5\%)-reported some menstrual health disruption or breast/chest tenderness (Additional file 1). The most reported issues were increased menstrual cramping in 604 (36.6\%), unusual spotting in 459 (27.8\%), increased bleeding in 389 (23.6\%), and more days of bleeding (312; 18.9\%). Respondents age 1833 were most likely to report menstrual/breast changes (69.7\%; 604 of 866). A majority of respondents age 34-50 years reported symptoms (59.2\%; 271 of 458$)$.
The frequency of any physical (except mouth-related) and/or psychological delayed health issues increased with a higher exposure to tear gas $(p<0.01)$ (Table 3).

We also observed a positive dose-response trend for all menstrual/breast/chest health issues $(p<0.01)$, except those in the "Other" category (Table 4).

\section{Psychological health issues}

Of 2257 respondents, 1635 (72.4\%) reported increased anxiety, startle response, fear, fatigue, or sadness/depressive feelings after the exposure (Table 3 and Additional file 1). These issues were more common among protesters $(73.7 \%$; 1546 of 2099) than those otherwise exposed $(56.3 \%, 89$ of 158). Respondents who selfidentified as persons of Black, American Indian/Alaska Native, Native Hawaiian/Pacific Islander, Asian or Hispanic race and/or ethnicity compared to White/non-Hispanic were equally likely to report mental health issues (81.4\%; 307 of 377 vs. $79.0 \%$; 1276 of $1615 ; p=0.29$, negligible association Cramer's $V=0.02$ ).

\section{Open-ended responses}

Overall, open-ended responses align with observed quantitative results; however, these provide insights into the duration of health issues and their severity. Additional health issues identified were sleep disturbances (e.g., insomnia, nightmares), prolonged fatigue, appetite suppression, and smell and taste disturbances.

Of the 923 respondents who provided open-ended feedback, 71 commented on new headaches that were severe and lasted for weeks in some. Forty-one commented on being nauseous for days. Thirteen persons reported having diarrhea, with blood in some persons, ranging from 1 day to over a month. Overall, openended responses on menstrual health changes from 163 persons align with the quantitative data. Many respondents noted that after their exposures, their menstrual cycle started days or weeks earlier or later and lasted longer, compared to their typical cycle. Seventy-three persons commented on being exhausted and unable to carry out their regular work for up to 5 days; a few wrote that fatigue lasted up to 2 weeks.

Thirty-two persons indicated worsening of an existing health condition after being exposed to tear gas. Conditions and symptoms included allergies, asthma attacks that required multiple or sustained treatments or symptoms that were not resolved with treatment, flares of eczema, fibromyalgia, Hashimoto's thyroiditis, rheumatoid arthritis, and herpes simplex virus. Sixteen persons reported injuries from projectiles (bruising, swelling, broken skin), two of which required staples or stitches. 
Table 2 Proportions of persons reporting health issues

\begin{tabular}{|c|c|c|c|c|c|c|c|c|}
\hline \multirow[t]{3}{*}{ Health issues categories } & \multicolumn{6}{|c|}{ Number of persons expressing health issues ${ }^{b}$} & \multirow{2}{*}{\multicolumn{2}{|c|}{$\begin{array}{l}\text { Change from } \\
\text { immediate to } \\
\text { delayed issues }\end{array}$}} \\
\hline & \multicolumn{2}{|c|}{ Either immediate or with a delay } & \multicolumn{2}{|c|}{ Immediately } & \multicolumn{2}{|c|}{ Delayed } & & \\
\hline & n & $\%$ & $\mathbf{n}$ & $\%$ & $\mathbf{n}$ & $\%$ & $\mathrm{n}$ & $\%$ \\
\hline Any physical or psychological health issues & 2116 & 93.8 & 2105 & 93.3 & 1944 & 86.1 & -161 & -7.6 \\
\hline Any physical health issues ${ }^{a}$ & 2114 & 93.7 & 2105 & 93.3 & 1823 & 80.8 & -282 & $-13.4^{\|}$ \\
\hline Eyes & 2001 & 88.7 & 1995 & 88.4 & 594 & 26.3 & -1401 & $-70.2^{\prime \prime}$ \\
\hline Nose & 1802 & 79.8 & 1790 & 79.3 & 437 & 19.4 & -1353 & $-75.6^{\| \prime}$ \\
\hline Mouth & 1542 & 68.3 & 1510 & 66.9 & 378 & 16.7 & -1132 & $-75.0^{\| \prime}$ \\
\hline Lungs and/or Chest & 1674 & 74.2 & 1569 & 69.5 & 1063 & 47.1 & -506 & $-32.2^{11}$ \\
\hline Skin & 1312 & 58.1 & 1238 & 54.9 & 495 & 21.9 & -743 & $-60.0^{\| \prime}$ \\
\hline Gastrointestinal & 808 & 35.8 & 453 & 20.1 & 638 & 28.3 & +185 & +40.8 \\
\hline Head & 920 & 40.8 & 610 & 27.0 & 626 & 27.7 & +16 & +2.6 \\
\hline Menstrual ${ }^{c, d}$ & 899 & 54.5 & $\mathrm{~N} / \mathrm{A}$ & & 899 & 54.5 & N/A & \\
\hline Psychological health issues & 1635 & 72.4 & $\mathrm{~N} / \mathrm{A}$ & & 1635 & 72.4 & N/A & \\
\hline
\end{tabular}

N/A not applicable

a Total count for the delayed physical issues includes menstrual health/breast/chest health

${ }^{b}$ Denominator was 2257 for any health issues, except 1650 for menstrual health

c Excludes cisgender men/males and transgender women

${ }^{d}$ For details for each menstrual/breast/chest health change, see Table 4 and Additional file 1

$\| p<0.01$ for the change

\section{Healthcare utilization}

The majority $(1233 ; 54.6 \%)$ of respondents reported receiving or planning to seek medical or mental healthcare for their tear gas-related health issues.

Receiving formal medical care (i.e., care provided by a clinician) or informal medical help (i.e., care provided by a non-clinician or a person with unknown training) was reported immediately after the exposure by $41.8 \%$ (944 of 2257) of respondents. Volunteer medics were the most commonly reported immediate providers of medical attention after exposure (504; 53.4\% of 944 receiving immediate care). Forty-one percent (383 of 944) reported getting medical attention from a protester who identified as a medic, nurse, doctor, or other healthcare providers. A similar proportion of individuals (421; $44.6 \%)$ reported receiving medical help from a protester

Table 3 Proportions of respondents reporting health changes by intensity of exposure

\begin{tabular}{|c|c|c|c|c|c|c|c|c|}
\hline \multirow[t]{3}{*}{ Delayed health issues categories } & \multicolumn{6}{|c|}{$\begin{array}{l}\text { Participants reporting health issues } \\
\text { by intensity of exposure }\end{array}$} & \multirow{2}{*}{\multicolumn{2}{|c|}{ Test of trend }} \\
\hline & \multicolumn{2}{|c|}{$\begin{array}{l}1 \text { day of exposure } \\
N=398\end{array}$} & \multicolumn{2}{|c|}{$\begin{array}{l}2-4 \text { days of exposure } \\
N=1391\end{array}$} & \multicolumn{2}{|c|}{$\begin{array}{l}\geq 5 \text { days of exposure } \\
N=468\end{array}$} & & \\
\hline & $\bar{n}$ & $\%^{a}$ & $\mathrm{n}$ & $\%^{a}$ & $\bar{n}$ & $\%^{a}$ & $p$ value & $Z$ value \\
\hline Any physical or psychological health issues & 309 & 77.6 & 1215 & 87.3 & 420 & 89.7 & $<0.01$ & -3.8 \\
\hline Any physical health issues ${ }^{a}$ & 290 & 72.9 & 1126 & 80.9 & 407 & 87 & $<0.01$ & -4.7 \\
\hline Eye & 91 & 22.9 & 356 & 25.6 & 147 & 31.4 & $<0.01$ & -3.0 \\
\hline Nose & 62 & 15.6 & 257 & 18.5 & 118 & 25.2 & $<0.01$ & -3.8 \\
\hline Mouth & 59 & 14.8 & 232 & 16.7 & 87 & 18.6 & 0.16 & -1.4 \\
\hline Lungs and/or Chest & 126 & 31.7 & 648 & 46.6 & 289 & 61.8 & $<0.01$ & -8.3 \\
\hline Skin & 57 & 14.3 & 294 & 21.1 & 144 & 30.8 & $<0.01$ & -5.8 \\
\hline Gastrointestinal & 77 & 19.3 & 358 & 25.7 & 203 & 43.4 & $<0.01$ & -8.5 \\
\hline Head & 91 & 22.9 & 385 & 27.7 & 150 & 32.1 & $<0.01$ & -2.8 \\
\hline Menstrual $^{\mathrm{b}}$ & 116 & 39.7 & 566 & 54.8 & 217 & 66.6 & $<0.01$ & -6.0 \\
\hline Psychological health issues & 204 & 51.3 & 1041 & 74.8 & 390 & 83.3 & $<0.01$ & -8.2 \\
\hline
\end{tabular}

${ }^{a}$ Total count for the delayed physical issues includes menstrual health/breast/chest health

${ }^{b}$ Denominators for exposure of 1 day, $2-4$ days, and $\geq 5$ days were 292; 1032, 326, respectively, because of the eligibility criteria for this outcome (see Table 4 for details) 
Table 4 Proportion of respondents reporting menstrual/breast health changes according to days of exposure

\begin{tabular}{|c|c|c|c|c|c|c|}
\hline \multirow{3}{*}{$\begin{array}{l}\text { Delayed menstrual/breast/chest health issues } \\
\text { categories }\end{array}$} & \multicolumn{6}{|c|}{ 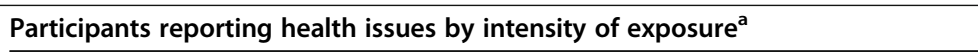 } \\
\hline & \multicolumn{2}{|c|}{$\begin{array}{l}1 \text { day of exposure } \\
N=292\end{array}$} & \multicolumn{2}{|c|}{$\begin{array}{l}2-4 \text { days of exposure } \\
N=1032\end{array}$} & \multicolumn{2}{|c|}{$\begin{array}{l}\geq 5 \text { days of exposure } \\
N=326\end{array}$} \\
\hline & $\mathbf{n}$ & $\%$ & $\mathbf{n}$ & $\%$ & n & $\%$ \\
\hline Any of menstrual/breast/chest health issues & 116 & 39.7 & 566 & 54.8 & 217 & 66.6 \\
\hline Increased menstrual cramping & 71 & 24.3 & 367 & 35.6 & 166 & 50.9 \\
\hline Unusual spotting & 56 & 19.2 & 273 & 26.5 & 130 & 39.9 \\
\hline Increased bleeding & 41 & 14.0 & 223 & 21.6 & 125 & 38.3 \\
\hline Increased number of days of spotting/bleeding & 34 & 11.6 & 179 & 17.3 & 99 & 30.4 \\
\hline Breast/chest tenderness & 23 & 7.9 & 136 & 13.2 & 74 & 22.7 \\
\hline Increased clots & 9 & 3.1 & 85 & 8.2 & 66 & 20.2 \\
\hline Change in the color of blood (spotting/bleeding) & 15 & 5.1 & 80 & 7.8 & 52 & 16.0 \\
\hline Absence of menstrual bleeding & 9 & 3.1 & 66 & 6.4 & 32 & 9.8 \\
\hline Decreased number of days of spotting/bleeding & 8 & 2.7 & 39 & 3.8 & 23 & 7.1 \\
\hline Other & 14 & 4.8 & 66 & 6.4 & 23 & 7.1 \\
\hline
\end{tabular}

${ }^{a}$ Cochran-Armitage Trend test: $p<0.01$ for all menstrual/breast/chest health issues, except "Other" $p=0.18$

who did not self-identify as a trained health provider, and six $(0.6 \%)$ respondents reported care at an onsite medical utility vehicle.

Six percent (136) reported receiving professional medical care with some delay after the exposure. Of those, $69(50.7 \%)$ reported visiting a health provider in-person or via telehealth, $30(22.0 \%)$ called an advice nurse, 20 (14.7\%) visited urgent care, and $14(10.3 \%)$ visited an emergency room. An additional 84 (3.7\%) persons reported planning to seek professional medical care.

Overall, 373 respondents (16.5\%) reported receiving mental healthcare following exposure to tear gas agents, and 249 (11.0\%) planned to seek mental care. We observed that a slightly higher proportion of respondents exposed at a protest reported receiving mental healthcare than those who were exposed other ways (355 [16.9\%] vs. 18 [11.4\%]; $p=0.07$, negligible association Cramer's $V=$ 0.04). Among respondents exposed other ways, persons of Black, American Indian or Alaska Native, Native Hawaiian or Pacific Islander, Asian, or Hispanic race and/or ethnicity were twice as likely to report receiving mental care as White/non-Hispanic respondents (6 [28.6\%] vs. 12 [12.5\%]; $p=0.09$, weak association Cramer's $V=0.18)$. This difference did not reach statistical significance.

\section{Discussion}

To our knowledge, this is the first large U.S. study that describes psychological and physical health issues and associated healthcare utilization by protesters and community-dwelling adults exposed to crowd-control agents. This cross-sectional study demonstrates that exposed persons commonly experienced health issues affecting multiple body systems, sometimes persisting for days to weeks and often requiring medical attention.
In the Portland, Oregon community, survey respondents reported typical health effects immediately following exposure, such as tearing and burning eyes, irritation of the upper and lower respiratory tract, and a burning sensation on the skin. These findings align with findings in small, retrospective studies conducted outside the U.S. [27-30]. In addition, respondents commonly reported delayed headaches, gastrointestinal issues, and menstrual changes that have not yet been reported in the peer-reviewed literature [8].

In our study, the majority $(1635 ; 72.4 \%)$ of respondents reported new mental health problems. Previously, it has been demonstrated that active or indirect participation in collective actions (e.g., protests) might result in a substantial increase in prevalence of anxiety symptoms, symptoms of major depression, and post-traumatic stress disorder [31].

We acknowledge that the high level of stress and anxiety experienced by our respondents may have been a contributing factor to the physical health issues they reported and sought care for. In terms of menstrual disruption, a definitive relationship between psychological stress and menstrual changes has not been established. While some research has shown delayed or missing menstrual cycles [32] and dysmenorrhea associated with stress [33], other studies, including the California Women's Reproductive Health Study, found no association between dysmenorrhea, hypomenorrhea, menorrhagia associated and stressful life events, though shorter cycle length and some cycle irregularities were observed $[34,35]$. While distress is a plausible contributor to the menstrual disruption reported in our study, we observed high rates of persons with early onset of menses, heavier menses, and an apparent dose-response association 
between tear gas exposure and spontaneous bleeding and breast/chest tenderness which has not been previously reported in the peer-reviewed literature. We found no studies of the endocrine effects of tear gas agents on humans; however, toxicological studies in animals suggest an association between CS gas and changes in the endocrine system [36, 37]. It is unclear if these effects from CS exposure in laboratory studies would be observed in humans. It also remains unknown which chemical agents were used against protesters in Portland. There remains the possibility that tear gas agents have endocrine-disrupting activity. The widespread anecdotal and lay media reports of menstrual changes by protesters after exposure to tear gas agents and in this study may warrant further research on potential endocrine effects of tear gas agents.

A key review on tear gas reported 9261 injuries in 5131 persons exposed to chemical irritants used for crowd control. Almost $9 \%$ of these injuries required professional medical management [8], although healthcare utilization was not captured comprehensively in the included studies. Our research indicates that the previously identified rate of healthcare utilization may be underestimated.

\section{Study considerations}

Major strengths of this study are its large sample size and the fact that we surveyed adults exposed to tear gas in different settings (i.e., at a protest or in their own neighborhoods). Additionally, we collected reports of both immediate and delayed health issues and identified several newly described health issues.

While the results of this survey paint a portrait of the potential effects of exposure to tear gas in a civilian population during a specified time window, there are limits to generalizability. This study was based on a cross-sectional, self-administered web-based survey. Selfreporting in this study is subject to recall bias. The rate of reported health effects may be overestimated due to the self-selected sample and reporting exposure to tear gas. We have not captured the severity of reported health issues, nor objectively assessed participants reporting symptoms. Finally, confounding factors (e.g., stress, anxiety) were present. Exposure to chemical agents at protests was inherently associated with exposure to other law enforcement tactics, including physical force, flash-bang grenades, rubber bullets, paintball guns, and long-range acoustical devices. The last limitation is that we did not use a correction for multiple comparisons. This could potentially lead to overestimating a statistical significance of some findings.

\section{Future research}

Further research on health consequences of exposure to chemical riot control agents is warranted. Studies should explore potential causal relationships between tear gas exposure and important health outcomes. Remaining research questions concern health effects in various populations-pregnant persons, newborns, children and adolescents, older adults, those with chronic conditions, and persons with social risk factors. Additionally, based on the menstrual health data presented here, is essential to determine if these agents can act as endocrine disruptors with the potential to impact reproductive health. Finally, the social injustice that prompted the 2020 Portland, OR protests-systemic racism and police brutality-and the violent interactions between protesters and law enforcement are factors that could contribute to immediate or sustained, novel mental health impacts in communities, which should be further explored.

\section{Public health implications}

The 1925 Geneva Protocol prohibits the use of tear gas agents during warfare, whereas the 1997 Chemical Weapons Convention explicitly permits use for certain law enforcement purposes.

There is growing attention to policy surrounding restrictions of these chemicals in the U.S.; as of August 2020, lawmakers in nine states, including Oregon [38], had introduced bills that would ban or limit the use of tear gas by police. Our findings may further inform policy on use of these chemical agents by law enforcement in the U.S. on general populations.

\section{Conclusions}

The short- and long-term effects of tear gas agents when used on women, children, pregnant persons, the elderly, and persons with pre-existing comorbidities and associated utilization of healthcare remain insufficient to inform policy. Our study demonstrates that community residents and protesters who reported being exposed to tear gas also commonly experienced health issues affecting multiple body systems, including previously undescribed menstrual disruption, sometimes persisting for days to weeks, and often requiring medical attention. The frequency of health issues reported increased with the exposure, indicating a potential dose-response.

\section{Abbreviations \\ COVID-19: Coronavirus Disease 2019; OR: Oregon (U.S. state)}

\section{Supplementary Information}

The online version contains supplementary material available at https://doi. org/10.1186/s12889-021-10859-w.

Additional file 1. Proportions of persons reporting health issues, detailed report.

\section{Acknowledgements}

The authors would like to thank Arthur Truong, MS (Kaiser Permanente Northwest) for programming the survey in REDCap software; Emily Schield, 
RN, John Ogden, and Kaija Maggard, MS (Kaiser Permanente Northwest) for survey review and beta testing; Jason Scott, MPH, MPP (Kaiser Permanente Northwest) for preliminary analysis; Lucy A. Savitz, PhD, MBA (Kaiser Permanente Northwest), Professor Jeanne-Marie Guise, MD, MPH (Oregon Health \& Science University), and Jill A. Pope, BA (Senior Technical Editor, Kaiser Permanente Northwest) for the careful review of a draft manuscript.

\section{Authors' contributions}

Six persons met all four International Committee of Medical Journal Editors (ICMJE) criteria for authorship (BNTO, KSM, MRP, EMK, AH, and II). Wrote the first draft of the paper BNTO, KSM, and II. Statistical analyses and interpretation: BNTO, KSM, EK, II. Other analyses of the results: BNTO, KSM, MRP, EMK, AH, and II. Contributed to the writing of the paper: BNTO, KSM, $M R P, E M K, A H$, and II. Agree with the manuscript's results and conclusions: BNTO, KSM, MRP, EMK, AH, and II. The author(s) read and approved the final manuscript.

\section{Funding}

Resources for survey design, data collection, analyses, and dissemination were made possible by the Learning Health System Program at the Center for Health Research. Dr. Ivlev was supported by grant number K12HS026370 from the Agency for Healthcare Research and Quality. The grantors had no role in the design, conduct, or reporting of the study. The content is solely the responsibility of the authors and does not necessarily represent the official views of the grantors disclosed above.

\section{Availability of data and materials}

The datasets generated and/or analyzed during the current study are not publicly available but are available from the corresponding author on reasonable request.

\section{Declarations}

\section{Ethics approval and consent to participate}

The Kaiser Permanente Northwest Institutional Review Board (IRB) determined that this activity is exempt from IRB review and approval (IRB ID: 00000405). All participants provided written informed consent to participate in the study.

\section{Consent for publication}

Not applicable.

\section{Competing interests}

The authors declare that they have no competing interests.

\section{Author details}

'Kaiser Permanente Northwest, Center for Health Research, $3800 \mathrm{~N}$ Interstate Ave, Portland, OR 97227, USA. ${ }^{2}$ Northwest Permanente P.C, 500 NE Multnomah St \#100, Portland, OR 97232, USA. ${ }^{3}$ University of Minnesota, School of Public Health, 420 Delaware St SE, Minneapolis, MN 55455, USA.

\section{Received: 28 December 2020 Accepted: 16 April 2021}

\section{Published online: 26 April 2021}

\section{References}

1. Rothenberg C, Achanta S, Svendsen ER, Jordt SE. Tear gas: an epidemiological and mechanistic reassessment. Ann N Y Acad Sci. 2016; 1378(1):96-107. https://doi.org/10.1111/nyas.13141.

2. Heisler M, Hampton K, McKay D. Dangerous use of crowd-control weapons against medics and protesters in Portland, OR. Lancet. 2020;396(10259):e5960. https://doi.org/10.1016/S0140-6736(20)32080-8.

3. Buchanan $L$, Bui $Q$, Patel JK. Black lives matter may be the largest movement in U.S. history. In: the New York times. New York: A. G Sulzberger; 2020. https://www.nytimes.com/interactive/2020/07/03/us/ george-floyd-protestscrowd-size.html. Accessed 18 Dec 2020.

4. Smith S, Wu J, Murphy J. Map: George Floyd Protests Around the World. the Protests That Started in the U.S. After the Death of George Floyd Have Gone Global. Track Where They Are. 2020. https://www.nbcnews.com/news/ world/map-george-floyd-protests-countries-worldwide-n1228391. Accessed 18 Dec 2020.
5. Bates L, Curry-Stevens A. The African American Community in Multnomah County: an unsettling profile. Portland: Portland State University; 2014.

6. KPTV. Study Tracks Use of Tear Gas as Portland Nears 70 Days of Protests. 2020. https://www.kptv.com/news/study-tracks-use-of-tear-gas-as-portlandnears-70-days-ofprotests/article_963a57c6-d6a8-11 ea-93b6-df94059985fc. html. Accessed 18 Dec 2020.

7. U.S. Food and Drug Administration. FDA Emergency Operations Plan. In: Services USDoHaH, ed. 3 ed: Office of Emergency Management; 2019.

8. Haar RJ, lacopino V, Ranadive N, Weiser SD, Dandu M. Health impacts of chemical irritants used for crowd control: a systematic review of the injuries and deaths caused by tear gas and pepper spray. BMC Public Health. 2017; 17(1):831. https://doi.org/10.1186/s12889-017-4814-6.

9. National Research Council. Acute Exposure Guideline Levels for Selected Airborne Chemicals: Volume 15. Washington, DC: The National Academies Press; 2013.

10. Blain PG. Tear Gases and Irritant Incapacitants. 1-Chloroacetophenone, 2 Chlorobenzylidene Malononitrile and Dibenz [B,F]-1,4-Oxazepine. Toxicol Rev. 2003. https://doi.org/10.2165/00139709-200322020-00005.

11. Olajos EJ, Salem H. Riot control agents: pharmacology, toxicology, Biochemistry and Chemistry. J Appl Toxicol. 2001;21(5):355-91. https://doi. org/10.1002/jat.767.

12. Worthington $E_{1}$ Nee PA. CS exposure-clinical effects and management. J Accid Emerg Med. 1999;16(3):168-70. https://doi.org/10.1136/emj.16.3.168.

13. Salem H, Gutting BW, Kluchinsky T, Boardman C, Tuorinsky S, Hout J. Riot control agents. In: Lenhart M, editor. Medical aspects of chemical Warefair 2nd ed. Falls Church: Office of The Surgeon General; 2008. p. 441-84.

14. U.S. Army Medical Research Institute of Chemical Defense. Roit-Control Agents. CS, CN, DM, and OC. In: Hurst G, Tuorinsky S, Madsen J, et al., editors. Medical Management Of Chemical Causalties Handbook. 4 ed. Aberdeen Proving Ground, MD; 2007

15. Schep $\sqcup$, Slaughter RJ, McBride DI. Riot control agents: the tear gases CN, CS and OC-a medical review. J R Army Med Corps. 2015;161(2):94-9. https:// doi.org/10.1136/jramc-2013-000165.

16. Gaffney AW, McCormick D, Woolhandler S, Himmelstein DU. US law enforcement crowd control tactics at anti-racism protests: a public health threat. Lancet. 2020; 396(10243):21. https://doi.org/10.1016/S0140-6736(20)31421-5.

17. Breakell A, Bodiwala GG. CS gas exposure in a crowded night Club: the consequences for an accident and emergency department. J Accid Emerg Med. 1998:15(1):56-7. https://doi.org/10.1136/emj.15.1.56.

18. Ni MY, Yao XI, Leung KSM, Yau C, Leung CMC, Lun P, et al. Depression and post-traumatic stress during major social unrest in Hong Kong: a 10-year prospective cohort study. Lancet. 2020;395(10220):273-84. https://doi.org/1 0.1016/S0140-6736(19)33160-5.

19. Adam-Troian J, Celebi E, Mahfud Y. Police use of force during street protests: a pressing public mental health concern. EClinicalMedicine. 2020; 26:100509. https://doi.org/10.1016/j.eclinm.2020.100509.

20. Celebi E, Adam-Troian J, Mahfud Y. Positive links between exposure to police violence, PTSD, and depression symptoms among yellow vests protesters in France. J Interpers Violence. 2020:088626052093586. https:// doi.org/10.1177/0886260520935863.

21. DeVylder J, Fedina L, Link B. Impact of police violence on mental health: a theoretical framework. Am J Public Health. 2020;110(11):1704-10. https://doi. org/10.2105/AJPH.2020.305874.

22. Centers for Disease Control and Prevention. Facts About Riot Control Agents Interim document. 2018. https://emergency.cdc.gov/agent/ riotcontrol/factsheet.asp. Accessed 2 Mar 2021.

23. Harris PA, Taylor R, Minor BL, Elliott V, Fernandez M, O'Neal L, et al. The REDCap consortium: building an International Community of Software Platform Partners. J Biomed Inform. 2019;95:103208. https://doi.org/10.1016/ j.jbi.2019.103208

24. Cohen J. Statistical power analysis for the behavioral sciences. New York: Routledge; 1988

25. Rea LM, Parker RA. Designing and conducting survey research: a comprehensive guide. 4th ed. San Francisco: Jossey-Bass Publishers; 1992.

26. U.S. Census Bureau. QuickFacts: Portland city, Oregon. 2019. https://www. census.gov/quickfacts/fact/table/portlandcityoregon. Accessed 5 Apr 2021

27. Anderson PJ, Lau GS, Taylor WR, Critchley JA. Acute effects of the potent Lacrimator O-Chlorobenzylidene Malononitrile (CS) tear gas. Hum Exp Toxicol. 1996:15(6):461-5. https://doi.org/10.1177/096032719601500601.

28. Karagama YG, Newton JR, Newbegin CJ. Short-term and long-term physical effects of exposure to CS spray. J R Soc Med. 2003:96(4):172-4. https://doi. org/10.1258/jrsm.96.4.172. 
29. Koul PA, Mir H, Shah TH, Bagdadi F, Khan UH. Effects of pepper grenade explosions on non-combatant bystanders. J Public Health Policy. 2014;35(4): 499-505. https://doi.org/10.1057/jphp.2014.15.

30. Arbak P, Bașer I, Kumbasar ÖO, Ülger F, Kilıçaslan Z, Evyapan F. Long term effects of tear gases on respiratory system: analysis of 93 cases. ScientificWorldJournal. 2014;2014:1-5. https://doi.org/10.1155/2014/963638,

31. Ni MY, Kim Y, McDowell I, Wong S, Qiu H, Wong IO, et al. Mental health during and after protests, riots and revolutions: a systematic review. Aust N Z J Psychiatry. 2020;54(3):232-43. https://doi.org/10.1177/ 0004867419899165.

32. Schliep KC, Mumford SL, Vladutiu CJ, Ahrens KA, Perkins NJ, Sjaarda LA, et al. Perceived stress, reproductive hormones, and ovulatory function: a prospective cohort study. Epidemiology. 2015. https://doi.org/10.1097/EDE. 0000000000000238.

33. Wang L, Wang X, Wang W, Chen C, Ronnennberg AG, Guang W, et al. Stress and Dysmenorrhoea: a population based prospective study. Occup Environ Med. 2004;61(12):1021-6. https://doi.org/10.1136/oem.2003.012302.

34. Nagma S, Kapoor G, Bharti R, Batra A, Batra A, Aggarwal A, et al. To evaluate the effect of perceived stress on menstrual function. J Clin Diagn Res. 2015. https://doi.org/10.7860/JCDR/2015/6906.5611.

35. Fenster L, Waller K, Chen J, Hubbard AE, Windham GC, Elkin E, et al. Psychological stress in the workplace and menstrual function. Am J Epidemiol. 1999;149(2):127-34. https://doi.org/10.1093/oxfordjournals.aje.a 009777

36. Chowdhury AR, Deshmukh MB, Raghuveeran CD, Nashikkar AB, Chatterjee AK. Histological changes in thyroid of rat under the acute exposure of OChloro-Benzylidine Malononitrile. Experientia. 1978;34(10):1327. https://doi. org/10.1007/BF01981449.

37. Nagarkatti M, Nagarkatti PS, Raghuveeran CD. Short-term toxicity studies of O-Chlorobenzylidene Malononitrile on Humoral immunity in mice. Toxicol Lett. 1981;8(1-2):73-6. https://doi.org/10.1016/0378-4274(81)90141-7.

38. Relating to the Use of Tools by Law Enforcement Agencies; and Declaring an Emergency. House Bill 4208 (HB 4208-A), Oregon 2020. https://olis.leg.sta te.or.us/liz/2020S1/Measures/Overview/HB4208. Accessed 18 Dec 2020.

\section{Publisher's Note}

Springer Nature remains neutral with regard to jurisdictional claims in published maps and institutional affiliations.

Ready to submit your research? Choose BMC and benefit from:

- fast, convenient online submission

- thorough peer review by experienced researchers in your field

- rapid publication on acceptance

- support for research data, including large and complex data types

- gold Open Access which fosters wider collaboration and increased citations

- maximum visibility for your research: over $100 \mathrm{M}$ website views per year

At $\mathrm{BMC}$, research is always in progress.

Learn more biomedcentral.com/submissions 